\title{
Erratum to: Stochastic phenotypic interconversion in tumors can generate heterogeneity
}

\author{
Giuseppina Simone $e^{1,2}$
}

Published online: 15 July 2017

๑) European Biophysical Societies’ Association 2017

\section{Erratum to: Eur Biophys J (2017) 46:189-194 DOI 10.1007/s00249-016-1190-6}

The original article was published with the following errors:

In the "Result" section, the second sentence in the second paragraph was incorrect. The correct sentence should read as:
"The cells included two main subpopulations: cytokeratin positive $\left(\mathrm{CK}_{20} 0^{+}\right.$and $\left.\mathrm{CD}^{+} 5^{+}\right)$, defined as epithelial cancer cells, and cytokeratin negative $\left(\mathrm{CK} 20^{-}\right.$and $\left.\mathrm{CD}^{4} 5^{+}\right)$, defined as residual hematological contaminant cells (Malara et al. 2014)".

The caption of the $X$-axis in Fig. $2 d-g$ were incorrect. Figure 2 with correct caption is given below:

The online version of the original article can be found under doi:10.1007/s00249-016-1190-6.

Giuseppina Simone

giuseppina.simone@nwpu.edu.cn

1 Mechanical Engineering, Microsystem, Northwestern

Polytechnical University, 127 West Youyi Road,

Xi'an Shaanxi 710072, People's Republic of China

2 University of Naples Federico II, Piazzale Tecchio 80, 80125 Naples, Italy 


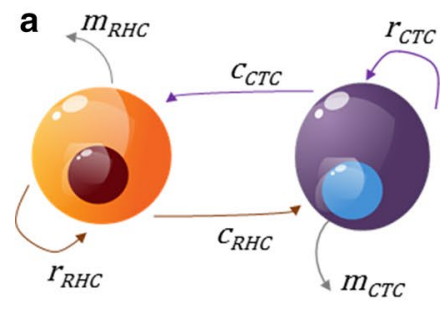

b

MODEL

$\mathrm{CTC} \longrightarrow$ null

$\mathrm{CTC} \longrightarrow \mathrm{CTC}$

$\mathrm{CTC} \rightleftharpoons \mathrm{RHC}$

$\mathrm{RHC} \longrightarrow$ null

$\mathrm{RHC} \rightarrow \mathrm{RHC}$

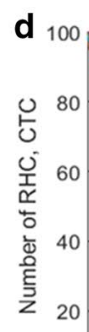

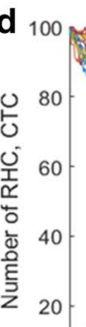

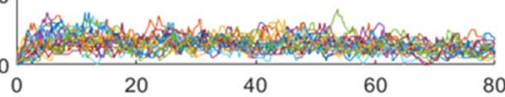

Parameters, $\left[\mathrm{t}^{-1}\right]$

$\mathrm{r}_{1}=\mathrm{c}_{1} \mathrm{C}_{\mathrm{CTC}} \quad \mathrm{c}_{1}=0.001$ $\mathrm{r}_{2}=\mathrm{C}_{2} \mathrm{C}_{\mathrm{CTC}} \quad \mathrm{C}_{2 \mathrm{f}}=0.03$ $\mathrm{r}_{3}=\mathrm{C}_{3} \mathrm{C}_{\mathrm{RHC}}-\mathrm{C}_{3 \mathrm{r}} \mathrm{C}_{\mathrm{CTC}} \quad \mathrm{C}_{2 \mathrm{r}}=0.3$ $\mathrm{r}_{4}=\mathrm{C}_{4} \mathrm{C}_{\mathrm{RHC}}$ $\mathrm{r}_{5}=\mathrm{c}_{5} \mathrm{C}_{\mathrm{RHC}} \quad \mathrm{c}_{5}=0.06$

C CTC RHC $\left[\begin{array}{l}0.75 \\ 0.38\end{array}\right.$

$\mathrm{RHC}$

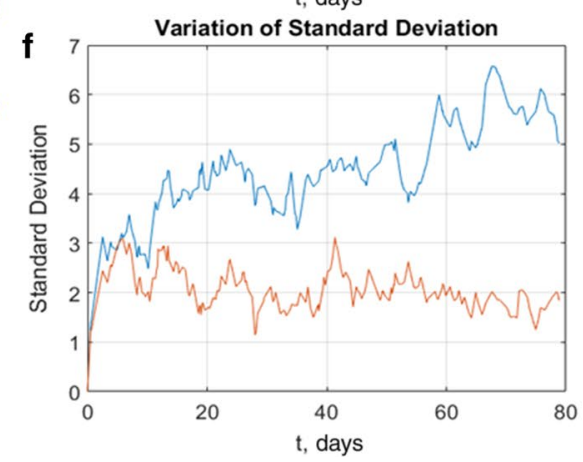

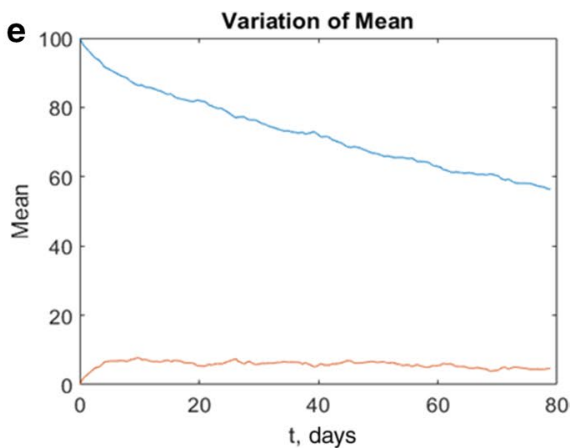

$\mathbf{g}$

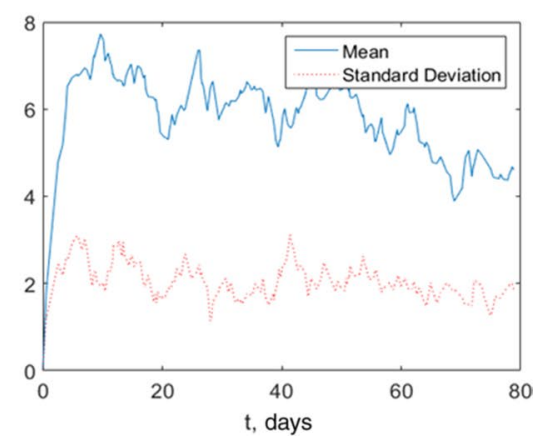

Fig. 2 a Transition matrix for the Markov model. $R H C$ and $C T C$ represent the two states of the system; cells in state CTC can replicate with rate coefficient $r_{\mathrm{CTC}}$, are cleared with rate coefficient $m_{\mathrm{CTC}}$, and convert to RHC phenotype with rate coefficient $c_{\mathrm{CTC}}$. Analogous rate coefficients describe the dynamics of the RHC subpopulation. b Biochemical model for describing the transition. c Matrix of probabili- ties related to the model and the experimental results. $\mathbf{d} N$-loop of the stochastic model. Profile of a number of RHC and CTC. e Variation of the mean based on curves in (d). $\mathbf{f}$ Variation of standard deviation based on curves (d). $\mathbf{g}$ Variation of the mean and standard deviation for CTC 